\title{
Hubungan Pengetahuan, Pendidikan, Dukungan Keluarga, Ibu Bekerja Dengan Pemberian ASI Perah Pada Anak Usia 0-2 Tahun DI Wilayah Kerja Puskesmas Gembor Kota Tanggerang
}

\author{
${ }^{1}$ Ria Setia Sari*,2Ani Rifathul Rizqi \\ ${ }^{1}{ }^{2}$ Program S1 Keperawatan, STIKES Yatsi Tangerang \\ *Email : riasetia233@gmail.com
}

\section{Kata Kunci : \\ Pengetahuan, \\ Pendidikan, \\ Dukungan \\ Keluarga, Ibu \\ Bekerja, Asi Perah. \\ Keywords : \\ Knowledge, \\ Education, Family \\ Support, Working \\ Mothers, dairy \\ Age.}

Info Artikel:

Tanggal dikirim:

13 Oktober 2020

Tanggal revisi:

3 November 2020

Tanggal diterima:

4 November 2020

DOI Artikel: 10.33862/citradeli ma.v4i2.139

Halaman: 129-135

\begin{abstract}
Abstrak
ASI Perah adalah ASI yang diambil dengan cara diperah atau memerah dari payudara ibu. Pentingnya pengetahuan ibu bekerja tentang memberikan ASI dapat berkurang dengan adanya metode ASI Perah. Tujuan Penelitian untuk mengetahui pengetahuan, pendidikan, dukungan keluarga, ibu bekerja dengan pemberian asi perah. Metode penelitian menggunakan deskriptif korelasi dengan pendekatan cross sectional. Populasi berjumlah 162 dan sampel berjumlah 60 . Pengumpulan data menggunakan kuesioner. Analisa data menggunakan chi-square. Hasil menunjukkan terdapat hubungan yang signifikan pengetahuan, pendidikan, dan ibu bekerja dengan pemberian asi perah dengan nilai $P$-value $<0,05$ sedangkan untuk dukungan keluarga dengan pemberian asi perah tidak terdapat hubungan karena nilai $P$-value $>0,05$. Hasil penelitian ada hubungan pengetahuan, pendidikan, ibu bekerja dengan pemberian asi perah, sedangkan hubungan dukungan keluarga dengan pemberian asi perah tidak memiliki hubungan pada anak usia 0-2 tahun di wilayah kerja Puskesmas Gembor Kota Tangerang Tahun 2019.

\section{The Relationship Between Knowledge, Eudcation, Family Support, Working The Gembor Health Centre Tangerang City} Mothers With Breastfeeding For Children Aged 0-2 Years In The Work Area Of
\end{abstract}

\begin{abstract}
Breast milk is breast milk that is taken by milking or milking from the mother's breast. The importance of working mother's knowledge about breastfeeding can be reduced by the presence of the Dairy Milking method. Research Objectives to find out knowledge, education, family support, working mothers with breastfeeding. The research method uses descriptive correlation with cross sectioanal approach. The population is 162 and the sample is 60 . The data collection uses a questionnaire. Data analysis uses chi-square. The results showed that there was a significant relationship between knowledge, education, and working mothers by giving breast milk with a p-value $<0,05$ while for family support with giving breast milk there was no relationship because the P-value $>0,05$. The results of the study there is a relationship of knowledge, education, working mothers by giving breast milk, while the relationship of family support with breastfeeding does not have a relationship in children aged 0-2 years in the working area of Gembor Health Center Tangerang City in 2019.
\end{abstract}




\section{PENDAHULUAN}

ASI Perah adalah ASI yang diambil dengan cara diperah atau memerah dari payudara ibu kemudian ASI yang telah diperah tersebut disimpan yang nantinya akan diberikan untuk bayi, bahkan ASI memiliki sumber gizi utama, memerah ASI bisa secara manual yaitu menggunakan tangan ibu atau menggunakan alat bantu memerah berupa alat pompa ASI bahkan bisa juga menggunakan cara keduanya secara bergantian sesuai dengan kondisi (Maryunani, 2015). Memerah dengan menggunakan tangan dapat menghasilkan stimulus sentuhan yang memicu hormon laktasi sehingga memungkinkan ibu untuk dapat memilih daerah-daerah khusus pada payudara jika terdapat adanya saluran yang menyumbat dalam proses memerah. Apabila pemerahan yang dilakukan dengan menggunakan tangan merupakan satu-satunya cara agar dapat mengosongkan payudara, maka memerah ASI paling sedikit delapan kali sehari dan menjadi rutinitas ibu untuk memerah ASI, terutama pada malam hari karena kadar prolaktin paling tinggi (Pollard, 2019).

Menurut WHO (2016), cakupan ASI Eksklusif di seluruh belahan dunia hanya sekitar $36 \%$ selama periode 2007-2014. Berdasarkan hasil Riskesdas (2012), cakupan pemberian ASI Eksklusif di Indonesia sebesar 54,3\%, yang memiliki presentase tertinggi yaitu di wilayah Provinsi NTB sebesar 79,7\% dan terendah di wilayah Provinsi Maluku sebesar 25,2\% (Balitbangkes, 2013). Menurut United Nation International Childern's Emergency Fund (UNICEF) dan World Health Organization (WHO) agar dapat menurunkan angka kematian pada anak maka direkomendasikan agar anak hanya dapat disusui dengan Air Susu Ibu (ASI) paling sedikit enam bulan dan berharap dengan adanya penerapan pemberian ASI Eksklusif dapat menurunkan Angka Kematian Bayi (AKB) (Kementrian Kesehatan RI, 2014). Pengetahuan ibu dalam menyusui terhadap pentingnya pemberian ASI dengan pemahaman menyusui yang benar juga tentang cara memerah ASI dan penyimpanan ASI pada ibu menyusui yang bekerja masih kurang (Depkes RI, 2013).

Pendidikan adalah suatu faktor yang dapat mempengaruhi pengetahuan dan sikap seseorang terhadap suatu perilaku kesehatan. Orang yang berpendidikan tinggi akan memberikan respon yang lebih rasional dari pada mereka yang berpendidikan rendah, lebih kreatif dan lebih terbuka terhadap usahausaha pembaharuan, dia juga lebih dapat menyesuaikan diri terhadap perubahan-perubahan social (Yunita,
2012). Dukungan keluarga adalah sikap, tindakan penerimaan keluarga terhadap keluarganya, berupa dukungan informasional, dukungan penilaian, dukungan instrumental dan dukungan emosional, bentuk suatu hubungan interpersonal yang meliputi sikap, tindakan dan penerimaan terhadap anggota keluarga, sehingga anggota keluarga merasa ada yang memperhatikannya (Friedman, 2010). Berdasarkan hasil studi pendahuluan peneliti di wilayah kerja puskesmas gembor didapatkan hasil 6 dari 10 responden yang memiliki status bekerja dan dapat memberikan ASI melalui metode ASI Perah.

Fenomena tersebut perlu diteliti agar masalah pengetahuan ibu yang bekerja tentang pentingnya memberikan ASI kepada bayi dapat berkurang dengan adanya metode ASI Perah sehingga asupan nutrisi bayi tercukupi dengan baik dan tidak menganggu masa perkembangan nya. Berdasarkan uraian di atas perlu diteliti "Hubungan Pengetahuan, Pendidikan, Dukungan keluarga, Ibu Bekerja dengan Pemberian ASI Perah pada Anak Usia 0-2 Tahun di wilayah kerja Puskesmas Gembor Kota Tangerang.

\section{METODE}

Jenis penelitian ini adalah penelitian kuantitatif dengan menggunakan desain analitik deskriptif dengan pendekatan cross sectional untuk mengetahui hubungan pengetahuan, pendidikan, dukungan keluarga, ibu bekerja dengan pemberian asi perah pada anak usia 0-2 tahun di wilayah kerja puskesmas gembor kota tangerang. Jumlah sampel dalam penelitian ini berjumlah 60 responden. Pengambilan sampel dalam penelitian ini menggunakan tekhnik total sampling. Kriteria Inklusi Ibu bekerja yang masih aktif dalam memberikan asi perah dan ibu bekerja yang mempunyai riwayat pemberian asi perah.

Instrumen yang digunakan dalam penelitian ini dibuat dalam bentuk kuesioner. Kuesioner yang pertama berupa data demografi yang terdiri dari pendidikan terakahir dan status pekerjaan ibu. Kuesioner yang kedua berupa pertanyaan dengan jawaban Ya atau Tidak untuk responden dalam pemberian asi perah. Kuesioner yang ke tiga berupa pengetahuan ibu bekerja tentang pemberian ASI Perah dan Kuesioner ke empat berupa dukungan keluarga dengan pemberian ASI Perah. Uji validitas dengan 20 responden nilai $\mathrm{r}$ tabel product moment person dengan $\mathrm{df}=20-2=18$, maka nilai $\mathrm{r}$ tabel $=0,444$.

Pengumpulan data yang dilakukan oleh peneliti dengan terlebih dahulu menentukan responden yang memenuhi kriteria eksklusi dan inklusi. Penelitian ini http://jurnalilmiah.stikescitradelima.ac.id/index.php/JI Vol.4 No.2 Januari 2021 
memberikan kebebasan (autonomy) kepada calon responden. Peneliti mendatangi rumah setiap calon responden ditemani bersama kader wilayah kerja Puskesmas Gembor Kota Tangerang dengan maksud dan tujuan penelitian, tata cara penelitian, manfaat, kerahasiaan data serta menanyakan kesediaan untuk menjadi responden dalam penelitian ini data yang dikumpulkan melalui kuesioner diolah dengan menggunakan teknik analisis univariat dan analisis bivariate. Analisis univariat berupa data demografi yang meliputi pendidikan terakhir dan status pekerjaan. Analisa bivariate untuk menguji "Hubungan pengetahuan, pendidikan, dukungan keluarga, ibu yang bekerja dengan pemberian ASI Perah pada anak usia 02 tahun", dan penelitian ini menggunakan metode uji chi-square.

\section{HASIL DAN PEMBAHASAN Hasil Analisa Univariat}

\section{Tabel 1}

Disitribusi Frekuensi Karakteristik Responden Berdasarkan Riwayat Pendidikan dan Status Pekerjaan

\begin{tabular}{lcc}
\hline Karakteristik & Frekuensi & Presentase \\
\hline Pendidikan & & \\
SMA & 17 & $28,3 \%$ \\
D3 & 6 & $10,0 \%$ \\
S1 & 37 & $61,7 \%$ \\
Total & 60 & $100 \%$ \\
\hline Status Pekerjaan & & \\
Karyawati & 17 & $28,3 \%$ \\
Guru & 10 & $16,7 \%$ \\
Pegawais & 29 & $48,3 \%$ \\
Bidan & 4 & $6,7 \%$ \\
Total & 60 & $100 \%$ \\
\hline
\end{tabular}

Berdasarkan tabel diatas dapat disimpulkan sebagaian responden mayoritas berpendidikan S1 sebanyak 37 responden $(61,7 \%)$, dan berdasarkan karakteristik status pekerjaan mayoritas pegawai sebanyak 29 responden $(48,3 \%)$.

\section{Hasil Analisa Bivariat}

Tabel 2

Hasil Crosstabulation Hubungan Pengetahuan dengan Pemberian Asi Perah

\begin{tabular}{lcccccc}
\hline Pengetahuan & \multicolumn{3}{c}{ Pemberian ASI Perah } & \multirow{2}{*}{ Total } \\
\cline { 2 - 5 } & \multicolumn{2}{c}{ Ya } & \multicolumn{2}{c}{ Tidak } & & \\
& $\mathrm{N}$ & $\%$ & $\mathrm{~N}$ & $\%$ & $\mathrm{~N}$ & $\%$ \\
Baik & 42 & 85,7 & 7 & 14,3 & 49 & 100 \\
Cukup & 0 & 0,0 & 11 & 100 & 11 & 100 \\
Total & 42 & 70 & 18 & 30 & 60 & 100 \\
\hline
\end{tabular}

Berdasarkan tabel diatas dapat disimpulkan sebagian responden mayoritas responden yang memiliki pengetahuan baik dan memberikan asi perah sebanyak 42 responden $(85,7 \%)$, sedangkan responden yang memiliki pengetahuan cukup dan tidak memberikan asi perah berjumlah 11 responden (100,0\%). Didapatkan hasil uji statistik nilai $\mathrm{P}$ value 0,000 yang berarti $\mathrm{P}$ value $<0,05$ maka dapat disimpulkan bahwa adanya hubungan pengetahuan dengan pemberian asi perah pada anak usia 0-2 tahun.

Tabel 3

Hasil Crosstabulation Hubungan Pendidikan dengan Pemberian Asi Perah

\begin{tabular}{|c|c|c|c|c|c|c|}
\hline \multirow{3}{*}{$\begin{array}{l}\text { Pendi } \\
\text { dikan }\end{array}$} & \multicolumn{4}{|c|}{ Pemberian ASI Perah } & \multicolumn{2}{|c|}{ Total } \\
\hline & \multicolumn{2}{|c|}{$\mathrm{Ya}$} & \multicolumn{2}{|c|}{ Tidak } & & \\
\hline & $\mathrm{N}$ & $\%$ & $\mathrm{~N}$ & $\%$ & $\mathrm{~N}$ & $\%$ \\
\hline SMA & 1 & 5,9 & 16 & 94,1 & 17 & 100 \\
\hline D3 & 6 & 10 & 0 & 0,0 & 6 & 100 \\
\hline $\mathrm{S} 1$ & 35 & 94,6 & 2 & 5,4 & 37 & 100 \\
\hline Total & 42 & 70 & 18 & 30 & 60 & 100 \\
\hline
\end{tabular}

Berdasarkan tabel diatas dapat disimpulkan sebagian responden mayoritas responden yang memiliki pendidikan terakhir S1 dan memberikan asi perah pada anaknya berjumlah 35 responden $(94,6 \%)$, sedangkan responden yang memiliki pendidikan terakhir SMA dan tidak memberikan asi perah pada anaknya berjumlah 16 responden $(94,1 \%)$. Didapatkan hasil uji statistik nilai $\mathrm{P}$ value 0,000 yang berarti $\mathrm{P}$ value < 0,05 maka dapat disimpulkan bahwa adanya hubungan pendidikan dengan pemberian asi perah pada anak usia 0-2 tahun.

Tabel 4

Hasil Crosstabulation Hubungan Dukungan Keluarga dengan Pemberian Asi Perah

\begin{tabular}{lllllll}
\hline Dukungan & \multicolumn{9}{l}{ Pemberian ASI Perah } & \multicolumn{3}{l}{ Total } \\
\cline { 2 - 7 } keluarga & Ya & \multicolumn{5}{c}{ Tidak } \\
& $\mathrm{N}$ & $\%$ & $\mathrm{~N}$ & $\%$ & $\mathrm{~N}$ & $\%$ \\
Baik & 40 & 69 & 18 & 31 & 58 & 100 \\
Kurang & 2 & 100 & 0 & 0,0 & 2 & 100 \\
Total & 42 & 70 & 18 & 30 & 60 & 100 \\
\hline
\end{tabular}

Berdasarkan tabel diatas dapat disimpulkan sebagian responden mayoritas responden yang mendapatkan dukungan keluarga dan memberikan asi perah pada anaknya berjumlah 40 responden (69.0\%), sedangkan responden yang kurang mendapatkan dukungan keluarga dan memberikan asi perah pada anaknya berjumlah 2 responden (100,0\%). Didapatkan hasil uji statistik nilai $\mathrm{P}$ value 1000 yang berarti $\mathrm{P}$ value $>0,05$ maka dapat disimpulkan bahwa

http://jurnalilmiah.stikescitradelima.ac.id/index.php/JI Vol.4 No.2 Januari 2021 
tidak adanya hubungan dukungan keluarga dengan pemberian asi perah pada anak usia 0-2 tahun.

\section{Tabel 5}

Hasil Crosstabulation Hubungan Ibu Bekerja dengan Pemberian Asi Perah

\begin{tabular}{lllllll}
\hline Status & \multicolumn{3}{l}{ Pemberian ASI Perah } & \multicolumn{2}{c}{ Total } \\
\cline { 2 - 5 } Pekerjaan & Ya & \multicolumn{3}{c}{ Tidak } & & \\
& $\mathrm{N}$ & $\%$ & $\mathrm{~N}$ & $\%$ & $\mathrm{~N}$ & $\%$ \\
Karyawati & 1 & 5,9 & 16 & 94,1 & 17 & 100 \\
Guru & 9 & 90 & 1 & 10 & 10 & 100 \\
Pegawai & 28 & 96,6 & 1 & 3,4 & 29 & 100 \\
Bidan & 4 & 100 & 0 & 0,0 & 4 & 100 \\
Total & 42 & 70 & 18 & 30 & 60 & 100 \\
\hline
\end{tabular}

Berdasarkan tabel diatas dapat disimpulkan sebagian responden mayoritas responden responden yang memiliki status pekerjaan sebagai pegawai dan memberikan asi perah pada anaknya berjumlah 28 responden $(96,6 \%)$, sedangkan responden yang memiliki status pekerjaan sebagai karyawati dan memberikan asi perah pada anaknya berjumlah 1 responden $(5,9 \%)$. Didapatkan hasil uji statistik nilai $\mathrm{P}$ value 0,000 yang berarti $\mathrm{P}$ value $<0,05$ maka dapat disimpulkan bahwa adanya hubungan ibu bekerja dengan pemberian asi perah pada anak usia 0-2 tahun.

\section{PEMBAHASAN}

\section{Hubungan pengetahuan dengan pemberian ASI Perah}

Pengetahuan yang didapatkan dari ibu menyusui dalam kategori baik, cukup, atau pun kurang dikarenakan adanya beberapa faktor yang dapat mempengaruhi pengetahuan ibu seperti faktor internal yaitu kesehatan jasmani serta rohani seseorang, termasuk didalamnya adalah kesehatan indera, kesehatan psikis, intelektual, psikomotorik, serta kondisi afektif dan kognitif seseorang. Selain itu juga dapat dipengaruhi dari faktor ekternal yang meliputi seperti : pendidikan, paparan media masa, ekonomi, hubungan sosial, pengalaman, pekerjaan, umur, lingkungan, dan intelegensi (Wawan, 2011).

Hasil penelitian yang dilakukan di wilayah kerja Puskesmas Gembor Kota Tangerang sangat terbantu oleh peran kader di wilayah kerja puskesmas gembor kota tangerang pada saat penelitian dilakukan peneliti dan kader mendatangi rumah-rumah calon responden dan setelah bertemu dengan responden peneliti harus menjelaskan maksud dan tujuan namun ada beberapa yang tidak mau untuk menjadi responden karena beberapa faktor sehingga peneliti tidak bisa memaksakan hak responden.
Hasil penelitian ini sejalan dengan penelitian yang telah dilakukan oleh Sunesni, Dea dan Ananda Putri pada tahun 2018 yang membahas tentang Hubungan pendidikan dan pengetahuan ibu tentang ASI Perah dengan praktek pemberian ASI Perah di Desa Tanjung Aur Kelurahan Balai Gadang, Padang menunjukkan bahwa ibu yang memiliki pengetahuan baik berjumlah 7 responden $(19,4 \%)$ dan yang memiliki pengetahuan kurang baik berjumlah 29 responden (80,6\%), maka total keseluruhan berjumlah 36 responden.

Hasil penelitian yang telah dilakukan oleh Wiwi Sartika pada tahun 2015 yang membahas tentang Hubungan pengetahuan ibu bekerja tantang asi perah terhadap pemberian asi perah di Puskesmas Simpang Baru Riau mengatakan bahwa ibu yang memiliki pengetahuan baik berjumlah 34 responden $(54,0 \%)$ dan ibu yang memiliki pengethuan kurang berjumlah 29 responden $(46,0 \%)$, maka total keseluruhan berjumlah 63 responden.

Berdasarkan data diatas dapat disimpulkan bahwa penelitian ini memiliki hubungan antara pengetahuan ibu dengan pemberian asi perah di wilayah kerja Puskesmas Gembor Kota Tangerang.

\section{Hubungan pendidikan dengan pemberian ASI Perah}

Pendidikan secara umum adalah segala upaya yang direncanakan untuk mempengaruhi orang lain baik individu, kelompok atau masyarakat sehingga mereka melakukan apa yang diharapkan oleh pelaku pendidikan. Sehingga pendidikan seseorang juga dapat memepengaruhi pengethuannya dalam setiap melakukan tindakan (Notoatmodjo, 2010).

Hasil penelitian yang telah dilakukan di wilayah kerja Puskesmas Gembor Kota Tangerang sangat terbantu oleh peran kader di wilayah kerja puskesmas gembor kota tangerang pada saat penelitian dilakukan peneliti dan kader mendatangi rumah-rumah calon responden dan setelah bertemu dengan responden peneliti harus menjelaskan maksud dan tujuan dan menjelaskan pengisian identitas namun ada beberapa responden yang lupa dalam mencatat pendidikan terakhir nya sehingga peneliti harus mendatangi kembali rumah responden dan memberitahu responden untuk mengisi kuesioner yang belum terisi dengan jelas.

Hasil penelitian ini sejalan dengan penelitian yang telah dilakukan oleh Sunesni, Dea dan Ananda

http://jurnalilmiah.stikescitradelima.ac.id/index.php/JI Vol.4 No.2 Januari 2021 
Putri pada tahun 2018 yang membahas tentang Hubungan pendidikan dan pengetahuan ibu tentang ASI Perah dengan praktek pemberian ASI Perah di Desa Tanjung Aur Kelurahan Balai Gadang, Padang. Menunjukkan bahwa ibu yang mempunyai tamatan pendidikan kurang dari SMA berjumlah 21 responden dan ibu yang mempunyai tamatan pendidikan lebih dari SMA berjumlah 15 responden, maka total keseluruhan dalam penelitian ini berjumlah 36 responden.

Hasil penelitian yang telah dilakukan oleh Ory Okawary pada tahun 2015 yang membahas tentang Hubungan status pekerjaan ibu dengan pemberian ASI Eksklusif di wilayah kerja puskesmas Seyegan Sleman Yogyakarta mengatakan bahwa mayoritas jenjang pendidikan ibu adalah lulusan SLTA dengan 34 responden $(63,0 \%)$, dan minoritas adalah lulusan SLTP dengan 6 responden $(11,1 \%)$, sedangkan yang lulusan perguruan tinggi sebanyak 14 respondem $(25,9 \%)$, maka total keseluruhan responden berjumlah 54 responden.

Hasil penelitian yang telah dilakukan oleh Wiwi Sartika pada tahun 2015 yang membahas tentang Hubungan pengetahuan ibu bekerja tantang asi perah terhadap pemberian asi perah di Puskesmas Simpang Baru Riau mengatakan bahwa mayoritas responden berpendidikan SMA berjumlah 34 responden $(53,9 \%)$ dan minoritas berpendidikan SMP berjumlah 4 responden $(6,3 \%)$, sedangkan yang berpendidikan SD berjumlah 9 responden $(14,3 \%)$, yang berpendidikan diploma berjumlah 10 responden $(15,9 \%)$, dan berpendidikan S1 berjumlah 6 responden $(9,5 \%)$, maka total keseluruhan responden berjumlah 63 responden.

Hasil penelitian yang telah dilakukan oleh Etik Sulistyorini dan Lilik Hanifah pada tahun 2017 yang membahas tentang Hubungan pengetahuan dan sikap ibu menyusui tentang cara memerah dan menyimpan asi di Posyandu Anggrek Sanggarahan Joho Sukoharjo mengatakan bahwa mayoritas ibu berpendidikan SMA berjumlah 17 responden $(51,5 \%)$ dan minoritas berpendidikan SD berjumlah 4 responden $(12,1 \%)$, sedangkan yang berpendidikan SMP berjumlah 7 responden dan yang berpendidikan perguruan tinggi berjumlah 5 responden $(15,2 \%)$, maka total keseluruhan berjumlah 33 responden.

Berdasarkan data diatas dapat disimpulkan bahwa penelitian ini memiliki hubungan antara pendidikan ibu dengan pemberian asi perah di wilayah kerja Puskesmas Gembor Kota Tangerang.
Hubungan dukungan keluarga dengan pemberian ASI Perah

ukungan keluarga adalah sebuah proses yang terjadi sepanjang masa kehidupan. Sifat dan jenis dukungan berbeda dalam berbagai tahap-tahap kehidupan. Dukungan keluarga terdapat berupa dukungan social internal, seperti dukungan dari suami, isteri atau dukungan dari saudara kandung, dan dapat juga berupa dukungan keluarga eksternal bagi keluarga inti. Dukungan keluarga membuat keluarga membuat keluarga mampu berfungsi dengan berbagai kepandaian dan akal, sebagai akibatnya, hal ini meningkatkan kesehatan dan adaptasi keluarga (Friedman, 2010).

Hasil penelitian ini telah dilakukan di wilayah kerja Puskesmas Gembor Kota Tangerang sangat terbantu oleh peran kader dan juga anggota keluarga responden karena ada beberapa responden yang sedang tidak ada dirumah sehingga kuesioner di titipkan kepada anggota keluarga dan ke esokan hari peneliti kembali datang dan membuat janji untuk bertemu dengan responden agar peneliti dapat menjelaskan maksud dan tujuan penelitian ini.

Hasil penelitian ini sejalan dengan yang telah dilakukan oleh Novira Kusumayanti dan Triska Susila Nindya pada tahun 2016 yang membahas tentang Hubungan dukungan suami dengan pemberian ASI Eksklusif di wilayah Kecamatan Kademangan Blitar menujukkan bahwa ibu yang tidak memiliki dukungan suami berjumlah 18 responden $(27,3 \%)$ dan yang mendspatkan dukungan dari suami berjumlah 48 responden $(72,7 \%)$, maka total keseluruhan berjumlah 66 responden.

Hasil penelitian yang telah dilakukan oleh Arlia Purwaningsih, Oswati Hasanah, dan Wasisto Utomo pada tahun 2013 yang membahas tentang Hubungan dukungan keluarga terhadap manajemen laktasi pada ibu bekerja di Rumah Sakit Arifin Pekanbaru didapatkan rata-rata skor dukungan keluarga terhadap ibu bekerja adalah 15.26 dengan skor nilai tengah 16.00 (95\% CI 113.73 - 16.78). Standar deviasi yang dihasilkan besar 4.441. Skor dukungan keluarga terhadap ibu bekerja paling rendah 8 dan paling tinggi 22. Dari hasil estimasi interval dapat disimpulkan bahwa 95\% diyakini bahwa rata-rata skor dukungan keluarga adalah diantara 13.73 sampai dengan 16.78 . hasil ini menunjukkan rata-rata skor dukungan keluarga terletak pada skor pertengahan dimana skor ini mendekati nilai median.

Berdasarkan data diatas dapat disimpulkan bahwa penelitian ini tidak memiliki hubungan dukungan

http://jurnalilmiah.stikescitradelima.ac.id/index.php/JI Vol.4 No.2 Januari 2021 
keluarga dengan pemberian asi perah di wilayah kerja Puskesmas Gembor Kota Tangerang.

\section{Hubungan ibu bekerja dengan pemberian ASI Perah}

Bagi ibu yang bekerja, menyusui tidak perlu dihentikan. Ibu bekerja harus tetap memberikan ASI nya dan jika memungkinkan bayi dapat dibawa di tempat bekerja. Apabila tidak memungkinkan, ASI dapat diperah kemudian disimpan (Maryunani, 2015).

Hasil penelitian ini telah dilakukan di wilayah kerja Puskesmas Gembor Kota Tangerang sangat terbantu oleh peran kader di wilayah kerja puskesmas gembor kota tangerang karena dengan bantuan dan ditemani oleh kader untuk mendatangi rumah responden, dan kader juga cukup paham tentang keadaan responden terkait waktu dan kapan responden sedang ada dirumah.

Hasil penelitian ini sejalan dengan penelitian yang telah dilakukan oleh Ory Okawary pada tahun 2015 yang membahas tentang Hubungan status pekerjaan ibu dengan pemberian ASI Eksklusif di wilayah kerja puskesmas Seyegan Sleman Yogyakarta menunjukkan bahwa ibu yang memiliki status pekerjaan berjumlah 24 responden $(44,4 \%)$ dan ibu yang tidak memiliki status pekerjaan berjumlah 30 responden $(55,6 \%)$, maka total keseluruhan berjumlah 54 responden.

Hasil penelitian yang telah dilakukan oleh Etik Sulistyorini dan Lilik Hanifah pada tahun 2017 yang membahas tentang Hubungan pengetahuan dan sikap ibu menyusui tentang cara memerah dan menyimpan asi di Posyandu Anggrek Sanggarahan Joho Sukoharjo mengatakan bahwa ibu yang memiliki status bekerja berjumlah 15 responden $(45,5 \%)$, dan yang tidak memiliki status sebagai pekerja berjumlah 18 responden $(54,5 \%)$ maka total keseluruhan berjumlah 33 responden.

\section{KESIMPULAN}

Berdasarkan hasil uji statistik yang telah dilakukan di wilayah kerja Puskesmas Gembor Kota Tangerang Tahun 2019 berjumlah 60 responden di dapatkan data bahwa ibu yang memiliki pengetahuan baik dan memberian asi perah berjumlah 42 responden $(85,7 \%)$, sedangkan responden yang memiliki pendidikan terakhir S1 dan memberikan asi perah pada anaknya berjumlah 35 responden $(94,6 \%)$, dan responden yang memiliki status pekerjaan sebagai pegawai dan memberikan asi perah pada anaknya berjumlah 28 responden $(96,6 \%)$.
Dapat disimpulkan bahwa ada hubungan yang signifikan antara variabel pengetahuan, pendidikan, ibu bekerja dengan pemberian asi perah dengan didapatkan hasil dengan nilai $\mathrm{P}$-value $0,000<0,05$. Berdasarkan penelitian yang telah dilakukan di wilayah kerja Puskesmas Gembor Kota Tangerang Tahun 2019 berjumlah 60 responden di dapatkan data bahwa ibu yang mendapatkan dukungan keluarga dan memberikan asi perah pada anaknya berjumlah 40 responden $(69.0 \%)$, dan responden yang tidak mendapatkan dukungan keluarga dan tidak memberikan asi perah pada anaknya berjumlah 18 responden (31,0\%), sedangkan responden yang kurang mendapatkan dukungan keluarga dan memberikan asi perah pada anaknya berjumlah 2 responden $(100,0 \%)$, dan responden yang tidak mendapatkan dukungan keluarga dan tidak memberikan asi perah pada anaknya berjumlah $(0 \%)$.

Berdasarkan uji Chi-square didapatkan hasil bahwa nilai $\mathrm{P}$-value 1000 yang berarti $\mathrm{P}$ value $>0,05$ maka dapat disimpulkan bahwa tidak adanya hubungan dukungan keluarga dengan pemberian asi perah pada anak usia 0-2 tahun.

\section{DAFTAR PUSTAKA}

Cadwell Karin, Turner Cindy () Buku Saku Manajemen Laktasi. Jakarta : EGC

Corniawati, Inda, Sinaga A Elizabeth, Syukur N Abdul (2018). Hubungan Penegtahuan Ibu Bekerja Tentang ASI Perah dengan Praktek Pemberian ASI Perah di Puskesmaskarang Asam Tahun 2017. Mahakam midwifery jurnal. Vol. 2 No. 3, Mei 2018

Hastono, S.P. \& Sabri, L. (2010). Statistik Kesehatan. Jakarta : Rajawali Pers

Hidayah Luluk, Setyaningrum Utari (2018). Hubungan Pengetahuan Ibu Bekerja Tentang ASI Perah dengan Sikap Terhadap ASI Perah. Jurnal Ilmiah Bidan. Volume III. Nomor 12018

Kementrian Kesehatan RI. (2014) Profil Kesehatan Indonesia Tahun 2013. Jakarta : Kemenkes RI

Kusumayanti Novira, dan Nindya, T, Susuila (2017). Hubungan Dukungan Suami dengan Pemberian ASI Eksklusif di Daerah Perdesaan. Media gizi Indonesia. Vol 12 no. 2 Juli-Desember 2017

http://jurnalilmiah.stikescitradelima.ac.id/index.php/JI Vol.4 No.2 Januari 2021 
Maryunani Anik (2015) Insiasi Menyusu Dini, ASI EKSKLUSIF dan Manajemen Laktasi. Jakarta : Trans info media

Notoatmodjo, S. (2010) Metodelogi Penelitian Kesehatan. Jakarta : Rineka Cipta

Notoatmodjo, Soekidjo. (2018) Metode Penelitian Kesehatan. Jakarta : Rineka Cipta

Nurhayati Fitri, Nurfadilah Sofi (2018). Hubungan Pengetahuan Ibu Menyusui Tentang Pemberian Asi Perah dengan Pendidikan di Wilayah Kerja Puskesmas Cimahi Tengah. Jurnal Bidan. Volume 4 No. 02, Juli 2018.

Okawary Ory (2015). Hubungan Status Pekerjaan Ibu dengan Pemberian ASI Eksklusif di Wilayah Kerja Puskesmas Seyegan Sleman Yogyakarta. Program Studi Ilmu Keperawatan Sekolah Tinggi Ilmu Kesehatan 'Aisyiyah. Yogyakarta

Pollard Maria. (2019) ASI (Asuhan Berbasis Bukti) Jakarta : EGC

Purwandari Haryatiningsih, Mulyono, Suryanto (2014). Perkembangan Balita : Deteksi Dini dan Stimulasi Tumbuh Kembang Balita. Yogyakarta : Pustaka Pelajar.

Sartika, Wiwi (2015). Hubungan Pengetahuan Ibu Bekerja Tentang ASI Perah Terhadap Pemberian Asi di Puskesmas Simpang Baru. Program Studi D3 Kebidanan. Universitas Abdurab tahun 2015

Senesni, Dea, Putri Ananda (2018). Hubungan Pendidikan dan Pengetahuan Ibu Tentang ASI Perah dengan Praktek Pemberian ASI Perah. Jurnal Edurance 3. Juni 2018.

Sugiyono. (2015) Metodel Penelitian Kuantitatiuf Kualitatif Dan $R \& D$. Bandung : Alfabeta

Sulistyorini, Etik dan Hanifah Lilik (2018). Hubungan Pengetahuan dan Sikap Ibu Menyusui Tentang Cara Memerah dan Menyimpan ASI di Posyandu Anggrek Sanggrahan Joho Sukohardjo Tahun 2017. Jurnal Of Health Resseacrh.Vol 1 No. 1. Maret 2018

Wiji, R.N. (2013). ASI dan Pedoman Ibu Menyusui. Yogyakarta : Nuha Medika

Yanti, Rifa dan Ummi, Ella (2011). Deskriptif Tingkat Pengetahuan Ibu Bekerja Tentang Pemberian ASI Eksklusif Secara Tidak Langsung Pada Bayi di Rs Ibu dan Anak ERIA Bunda Suka Jadi Pecan Baru. Jurnal photon. Vol. 1 No. 2, Mei 2011
Sunesni, D., \& Putri, A. (2018). Hubungan Pendidikan dan Pengetahuan Ibu Tentang ASI perah dengan Praktek Pemberian ASI perah. Jurnal Endurance. 